\title{
Modified Pure Endoscopic Approach to Pineal Region : Proof of Concept of Efficient and Inexpensive Surgical Model Based on Laboratory Dissections
}

Choque-Velasquez, Joham

2018-09

Choque-Velasquez , J , Miranda-Solis , F , Colasanti , R, Angel Ccahuantico-Choquevilca , L \& Hernesniemi , J 2018 , ' Modified Pure Endoscopic Approach to Pineal Region : Proof of Concept of Efficient and Inexpensive Surgical Model Based on Laboratory Dissections ' , World Neurosurgery , vol. 117 , pp. 195-198 . https://doi.org/10.1016/j.wneu.2018.06.080

http://hdl.handle.net/10138/303792

https://doi.org/10.1016/j.wneu.2018.06.080

cc_by_nc_nd

acceptedVersion

Downloaded from Helda, University of Helsinki institutional repository.

This is an electronic reprint of the original article.

This reprint may differ from the original in pagination and typographic detail.

Please cite the original version. 


\section{Accepted Manuscript}

Modified pure endoscopic approach to the pineal region: a proof of concept of an efficient and inexpensive surgical model based on laboratory dissections

Joham Choque-Velasquez, MD, Franklin Miranda-Solis, MD, Roberto Colasanti, MD, Luis Angel Ccahuantico-Choquevilca, MS, Juha Hernesniemi, MD, PhD

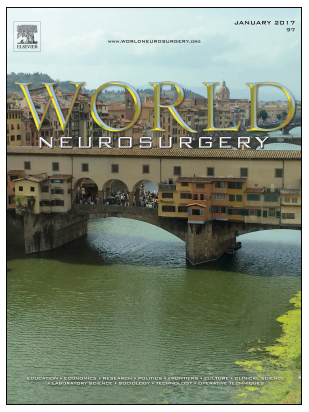

PII:

S1878-8750(18)31296-8

DOI:

10.1016/j.wneu.2018.06.080

Reference: WNEU 8393

To appear in: World Neurosurgery

Received Date: 25 March 2018

Revised Date: 11 June 2018

Accepted Date: 12 June 2018

Please cite this article as: Choque-Velasquez J, Miranda-Solis F, Colasanti R, Ccahuantico-Choquevilca LA, Hernesniemi J, Modified pure endoscopic approach to the pineal region: a proof of concept of an efficient and inexpensive surgical model based on laboratory dissections, World Neurosurgery (2018), doi: 10.1016/j.wneu.2018.06.080.

This is a PDF file of an unedited manuscript that has been accepted for publication. As a service to our customers we are providing this early version of the manuscript. The manuscript will undergo copyediting, typesetting, and review of the resulting proof before it is published in its final form. Please note that during the production process errors may be discovered which could affect the content, and all legal disclaimers that apply to the journal pertain. 


\section{Title Page}

\section{Title}

Modified pure endoscopic approach to the pineal region: a proof of concept of an efficient and inexpensive surgical model based on laboratory dissections

\section{Author names and affiliations:}

Joham Choque-Velasquez, MD, ${ }^{1,2}$ Franklin Miranda-Solis, MD, ${ }^{2,6}$ Roberto Colasanti, MD, ${ }^{4,5}$ Luis Angel Ccahuantico-Choquevilca, $\mathrm{MS},{ }^{3}$ Juha Hernesniemi, $\mathrm{MD}, \mathrm{PhD}^{1}$

${ }^{1}$ Department of Neurosurgery, Helsinki University Hospital, University of Helsinki, Helsinki, Finland

${ }^{2}$ Centro de Investigación en Anatomía y Fisiologia Alto Andina, Universidad Andina del Cusco, Cusco, Peru

${ }^{3}$ Centro Nacional de Plastinación y Técnicas Anatómicas, Universidad Nacional de San Antonio Abad del Cusco, Cusco, Perú

${ }^{4}$ Department of Neurosurgery, Umberto I General Hospital, Università Politecnica delle Marche, Ancona, Italy

${ }^{5}$ Department of Neurosurgery, Ospedali Riuniti Marche Nord, Pesaro, Italy

${ }^{6}$ Laboratorio de Microneuroanatomía, Universidad Andina del Cusco, Cusco, Peru

\section{Corresponding author:}

Joham Choque-Velasquez, MD

Department of Neurosurgery, Helsinki University Hospital,

Topeliuksenkatu 5, 00260 Helsinki, Finland

Email: johchove@hotmail.com 


\section{Abstract}

Objective: In the last decades endoscopic techniques have been increasingly used in neurosurgery as they may offer a valuable close-up view of the working area through a minimally invasive surgical corridor. Herein, we present an inexpensive and efficient endoscopic surgical model using a borescope, which was used for a "modified pure endoscopic approach" to the pineal region.

Methods: A borescope video camera was connected to a 16 inches personal computer monitor. A standard midline suboccipital craniotomy was performed on 2 cadaveric heads in the Concorde position. Then, a "borescopic" supracerebellar infratentorial approach was executed, thus reaching the pineal region which was exposed through an extensive arachnoid dissection.

Results: Using the above described model, we were able to provide excellent exposure of the main neurovascular structures of the pineal region, as showed by the intraoperative videos. In one of the specimen we identified an incidental pineal cyst that was meticulously dissected and removed.

Conclusion: Our proposed "borescopic" surgical model may represent an inexpensive and efficient alternative to conventional endoscopic techniques, and could be used for training purposes as well as even for clinical procedures, after a proper validation, particularly in economically challenging environments.

\section{Keywords:}

Borescope, Endoscope, Neuroendoscopy, Pineal region, Supracerebellar infratentorial approach, Surgical training

\section{Abbreviations and Acronyms}

MAPEnd, modified pure endoscopic approach 


\section{Introduction}

Pure endoscopic techniques represent novel minimally invasive procedures that have been developed during the last decades as alternatives to the conventional microsurgical approaches. Endoscopic techniques may provide an efficient visualization of deep neurovascular structures, a good illumination, and a valuable close-up view of the working area through minimally invasive surgical corridors. Moreover, endoscopic equipment is less expensive than surgical microscopes. ${ }^{1,2}$

Even though endoscopic techniques have been introduced years ago, first as endoscope-assisted and later as pure endoscopic procedures, the endoscopic surgical model is in continuous evolution pari passu with the technological development. ${ }^{3}$ Nonetheless, few reports regarding the use of pure endoscopic techniques for pineal region lesions have been published so far.

In this paper we present an inexpensive and efficient endoscopic surgical model using a borescope, which was used for a "modified pure endoscopic approach" (MAPEnd) to the pineal region.

\section{Methods}

The study was performed on two embalmed adult cadaveric heads. Our surgical training model for the MAPEnd required the following tools:

-a waterproof Borescope ${ }^{\circledR}$ Micro USB Inspection 3.5M Android, Video Camera 5mm;

-a portable computer;

-a conventional set for craniotomy;

-a set of long microinstruments. We have to remark that our microsurgical set was not fully equipped. Thus, we had to adapt some micro-curettes, sharp straight microdissectors, and blunt curved microdissectors (Figure 1).

The borescope video camera was connected to a 16 inches personal computer monitor. The borescope was held during the procedure by either the operator or an assistant.

Table 1 compares the costs of the traditional training systems to those of our training model.

\section{Surgical Procedure}

The head was placed in an adapted surgical pillow as for a Concorde position. ${ }^{4}$ A standard midline suboccipital approach was executed. Next, a wide suboccipital craniotomy was performed, exposing the transverse sinuses, the torcular herophili, and extending inferiorly to the level of the cisterna magna. The dura was opened via a U- 
shaped incision based on the transverse sinuses. Then, a "borescopic" retractor-less approach along the upper surface of the cerebellar hemisphere was performed. Some bridging veins were cut in order to enlarge the route the pineal region which was exposed through an extensive arachnoid dissection.

\section{Results}

We were able to accomplish a wide exposure of the pineal region in both the specimens. The borescope allowed a satisfactory view of the main neurovascular structures of the region, namely the deep venous system (the internal cerebral and basal veins converging on the vein of Galen), the P3 segments of the posterior cerebral artery, the medial posterior choroidal arteries, the posterior wall and part of the roof of the third ventricle, and the pineal gland (Figure 2 and Video 1, illustrating our "borescopic" surgical model).

In one of the specimen we identified an incidental pineal cyst that was meticulously dissected and removed (Video 2, illustrating our “borescopic” surgical model).

\section{Discussion}

Our anatomic prosection demonstrated that the MAPEnd to the pineal region we performed using a borescope and a conventional set of long microsurgical instruments could represent an inexpensive and efficient neurosurgical model.

The endoneurosurgery was introduced by Griffith in 1975 for fontanelle and persutural ventriculoscopy and endoscopic ventricular surgery in infants. ${ }^{5}$ Later, many authors used the endoscope during microsurgical operations, in the so-called endoscope-assisted procedures. As previously described, endoscopic assistance may be very helpful to better visualize the deepest extensions of intracranial lesions, while offering a better illumination and magnification compared to the microscope alone, particularly in some blind regions of the surgical field. In addition, the endoscope may allow a clearer distinction of the interface between the tumor and the surrounding eloquent structures. ${ }^{6-17}$

In 2008 Gore et al. reported the first application of a pure endoscopic supracerebellar infratentorial approach for dealing with a pineal cyst, a minimally invasive alternative to conventional microsurgical procedures that requires no exposure of the venous sinuses. ${ }^{1,18,19}$ However, potential bleeding coming from bridging veins and/or highly vascularized lesions may be extremely hard to control with the endoscopic instrumentation. Later, endoscope-controlled procedures to the pineal region were introduced. In this last model the instruments are not 
routinely passed through the endoscope ports, but they are used independently of the endoscope over the cerebellar surface in order to reduce the risks of potential complications. ${ }^{3,20}$

Differently from the previous reports, in our model we used an inexpensive borescope, which was connected to a 16 inches personal computer monitor. The borescope offered a satisfactory view of the main neurovascular structures of the pineal region. Moreover, HD or $4 \mathrm{~K}$ resolutions monitors could improve the quality of the system. In this regard, our model is designed for neurosurgical centers with low income resources where neuroendoscopic training using conventional neuroendoscopes would be expensive and almost impossible. Our proposed "borescopic" surgical model could effectively allow to train in performing different endoscopic techniques, in particular the so called modified pure endoscopic approaches where the instruments are passed over the cerebellar surface in order to reduce the risks of potential complications.

We used a conventional set of long microinstruments traditionally used in microscopic approaches. However, we believe that the development of dedicated endoscopic instruments is paramount to make safer endoscopic procedures.

For academic purposes, we performed a wide suboccipital craniotomy in order to illustrate the different steps of the standard supracerebellar infratentorial approach to our students. However, a small craniotomy of about 3-4 $\mathrm{cm}$ is enough to access to the pineal region through the MAPEnd we describe. ${ }^{1,3,20}$

The introduction of the endoscope under microscopic control is recommended in order to decrease the risk of accidental mechanical injury. ${ }^{21}$ However, we did not experience any inadvertent damage of neurovascular structures even if a microscope was not available, thanks to a careful insertion of the borescope.

Nonetheless, we believe that the integration between the endoscope and the microscope has to be refined in order to reduce, in a clinical setting, potential risks and any increase in the operative time., ${ }^{3,20}$

Moreover, the learning curve to master endoscopic techniques is steep as a lot of dexterity in the so-called "eyehands blind technique" is required. ${ }^{2}$

\section{Limitations}

This is a cadaveric prosection study and as such it carries all the well-known limitations of such study (brain consistency, lack of cerebrospinal fluid, etc.). Another limitation is represented by the absence, in our model, of a specific boroscope holder, and of proper microsurgical instruments that could allow more efficient procedures. 


\section{Conclusion}

In conclusion, the MAPEnd approach to the pineal region we developed using a borescope could represent an inexpensive and efficient alternative to conventional endoscopic techniques. Indeed, our model could be effectively used for training purposes, and, after a proper validation, even for clinical procedures, particularly in economically challenging environments. ${ }^{22,23}$

\section{Disclosure}

Prof. Juha Hernesniemi is an Aesculap consultant. The C. Ehrnrooth Foundation partially supports the present paper, which is part of the "Pineal region surgery" project. The authors have no personal financial or institutional interest in any of the drugs, materials, and devices described in this article.

\section{Acknowledgments}

Our deep thanks to Chris Shane Cruz Bolivar and Juan Diego Condori Saavedra for all their help to organize carefully the anatomic specimens and all the required equipment to perform the cadaveric dissections. 


\section{References}

1. Choque-Velasquez J, Colasanti R, Resendiz-Nieves JC, et al. Supracerebellar Infratentorial Paramedian Approach in Helsinki Neurosurgery: Cornerstones of a Safe and Effective Route to the Pineal Region. World Neurosurg. 2017;105:534-542. doi:10.1016/j.wneu.2017.06.007

2. Choque-Velasquez J, Colasanti R, Collan J, Kinnunen R, Jahromi BR, Hernesniemi J. Virtual reality glasses and "Eye-hands blind technique" for microsurgical training in Neurosurgery. World Neurosurg. January 2018. doi:10.1016/j.wneu.2018.01.067

3. Thaher F, Kurucz P, Fuellbier L, Bittl M, Hopf NJ. Endoscopic surgery for tumors of the pineal region via a paramedian infratentorial supracerebellar keyhole approach (PISKA). Neurosurg Rev. 2014;37(4):677-684. doi:10.1007/s10143-014-0567-1

4. Kobayashi S, Sugita K, Tanaka Y, Kyoshima K. Infratentorial approach to the pineal region in the prone position: Concorde position. Technical note. J Neurosurg. 1983;58(1):141-143. doi:10.3171/jns.1983.58.1.0141

5. Griffith HB. Technique of fontanelle and persutural ventriculoscopy and endoscopic ventricular surgery in infants. Childs Brain. 1975;1(6):359-363.

6. Iacoangeli M, Colasanti R, Esposito D, et al. Supraorbital subfrontal trans-laminar endoscope-assisted approach for tumors of the posterior third ventricle. Acta Neurochir (Wien). 2017;159(4):645-654. doi:10.1007/s00701-017-3117-0

7. Felbaum D, Syed HR, Ryan JE, Jean WC, Anaizi A. Endoscope-Assisted Combined Supracerebellar Infratentorial and Endoscopic Transventricular Approach to the Pineal Region: A Technical Note. Cureus. 2016;8(3):e520. doi:10.7759/cureus.520

8. Colasanti R, Tailor A-RA, Gorjian M, Zhang J, Ammirati M. Microsurgical and endoscopic anatomy of the extended retrosigmoid inframeatal infratemporal approach. Neurosurgery. 2015;11 Suppl 2:181-189; discussion 189. doi:10.1227/NEU.0000000000000632

9. Colasanti R, Tailor A-RA, Lamki T, Zhang J, Ammirati M. Maximizing the petroclival region exposure via a suboccipital retrosigmoid approach: where is the intrapetrous internal carotid artery? Neurosurgery. 2015;11 Suppl 2:329-336; discussion 336-337. doi:10.1227/NEU.0000000000000749 
10. Colasanti R, Tailor A-RA, Zhang J, Ammirati M. Functional Petrosectomy Via a Suboccipital Retrosigmoid Approach: Guidelines and Topography. World Neurosurg. 2016;87:143-154. doi:10.1016/j.wneu.2015.11.042

11. Colasanti R, Tailor A-RA, Zhang J, Ammirati M. Expanding the Horizon of the Suboccipital Retrosigmoid Approach to the Middle Incisural Space by Cutting the Tentorium Cerebelli: Anatomic Study and Illustration of 2 Cases. World Neurosurg. 2016;92:303-312. doi:10.1016/j.wneu.2016.05.020

12. Colasanti R, Lamki T, Tailor A-RA, Ammirati M. Recurrent atlantoaxial synovial cyst resection via a navigation-guided, endoscope-assisted posterior approach. Surg Neurol Int. 2014;5(Suppl 15):S567-569. doi:10.4103/2152-7806.148048

13. Iacoangeli M, Rienzo AD, Colasanti R, et al. A rare case of chordoma and craniopharyngioma treated by an endoscopic endonasal, transtubercular transclival approach. Turk Neurosurg. 2014;24(1):86-89. doi:10.5137/1019-5149.JTN.7237-12.0

14. Iacoangeli M, Di Rienzo A, Colasanti R, et al. Endoscopy-verified occult subependymal dissemination of glioblastoma and brain metastasis undetected by MRI: prognostic significance. OncoTargets Ther. 2012;5:449-456. doi:10.2147/OTT.S39429

15. Iacoangeli M, Di Rienzo A, Colasanti R, et al. Endoscopic Transnasal Odontoidectomy With Anterior C1 Arch Preservation and Anterior Vertebral Column Reconstruction in Patients With Irreducible Bulbomedullary Compression by Complex Craniovertebral Junction Abnormalities: Operative Nuance. Neurosurgery. doi:10.1227/NEU.0000000000001330

16. Iacoangeli M, Nasi D, Colasanti R, et al. Endoscopic Endonasal Odontoidectomy with Anterior C1 Arch Preservation in Rheumatoid Arthritis: Long-Term Follow-Up and Further Technical Improvement by Anterior Endoscopic C1-C2 Screw Fixation and Fusion. World Neurosurg. 2017;107:820-829. doi:10.1016/j.wneu.2017.08.063

17. Wu P, Colasanti R, Lee J, et al. Quantitative evaluation of different far lateral approaches to the craniovertebral junction using the microscope and the endoscope: a cadaveric study using a tumor model. Acta Neurochir (Wien). 2018;160(4):695-705. doi:10.1007/s00701-018-3502-3

18. Gore PA, Gonzalez LF, Rekate HL, Nakaji P. Endoscopic supracerebellar infratentorial approach for pineal cyst resection: technical case report. Neurosurgery. 2008;62(3 Suppl 1):108-109; discussion 109. doi:10.1227/01.neu.0000317380.60938.79 
19. Choque-Velasquez J, Colasanti R, Resendiz-Nieves J, et al. Praying sitting position for pineal region surgery: an efficient variant of a classic positioning in Neurosurgery. World Neurosurg. 2018.

20. Uschold T, Abla AA, Fusco D, Bristol RE, Nakaji P. Supracerebellar infratentorial endoscopically controlled resection of pineal lesions: case series and operative technique. J Neurosurg Pediatr. 2011;8(6):554564. doi:10.3171/2011.8.PEDS1157

21. Salma A, Ammirati M. Real time parallel intraoperative integration of endoscopic, microscopic, and navigation images: a proof of concept based on laboratory dissections. J Neurol Surg Part B Skull Base. 2012;73(1):36-41. doi:10.1055/s-0032-1304554

22. Choque-Velasquez J, Colasanti R, Baffigo-Torre V, et al. Developing the First Highly Specialized Neurosurgical Center of Excellence in Trujillo, Peru: Work in Progress-Results of the First Four Months. World Neurosurg. 2017;102:334-339. doi:10.1016/j.wneu.2017.01.063

23. Choque-Velasquez J, Colasanti R, Fotakopoulos G, Elera-Florez H, Hernesniemi J. Seven Cerebral Aneurysms: A Challenging Case from the Andean Slopes Managed with 1-Stage Surgery. World Neurosurg. 2017;97:565-570. doi:10.1016/j.wneu.2016.10.078 


\section{Figure Legends}

Fig.1 Standard midline suboccipital approach (A). A borescope video camera was connected to a 16 inches personal computer monitor held by the operator (B). Adapted microinstruments to perform the MAPEnd to the pineal region (C). D, Intraoperative picture demonstrating: the tentorium (1), right and left P3 segments of the posterior cerebral artery $(2,3)$, the drainage of the vein of Galen into the straight sinus (4), and some cortical branches of both superior cerebellar arteries (5). E, Intraoperative picture demonstrating: the P3 segment of the left posterior cerebral artery (3), the pineal gland (6), the right superior colliculus (7), right and left basal veins of Rosenthal $(8,9)$, the left internal cerebral vein $(10)$, the precentral cerebellar veins (11), the pineal vein (12). 
Table 1. Comparison of the costs of the traditional training systems to those of our training model

\begin{tabular}{|l|l|}
\hline Surgical Tools & Cost approx. (US Dollars) \\
\hline 1. Training surgical microscope & $5000-10000$ \\
\hline 2. Endoscope set $\left(0^{\circ}\right.$ and $30^{\circ}$ scopes), endoscope camera and monitor & $35000-60000$ \\
\hline 3. Our proposed system & $10-100$ \\
Waterproof Borescope & $1000-1500$ \\
Portable computer & $1010-1600$ \\
\hline Total cost & \\
\hline
\end{tabular}




\section{ACCEPTED MANUSCRIPT}

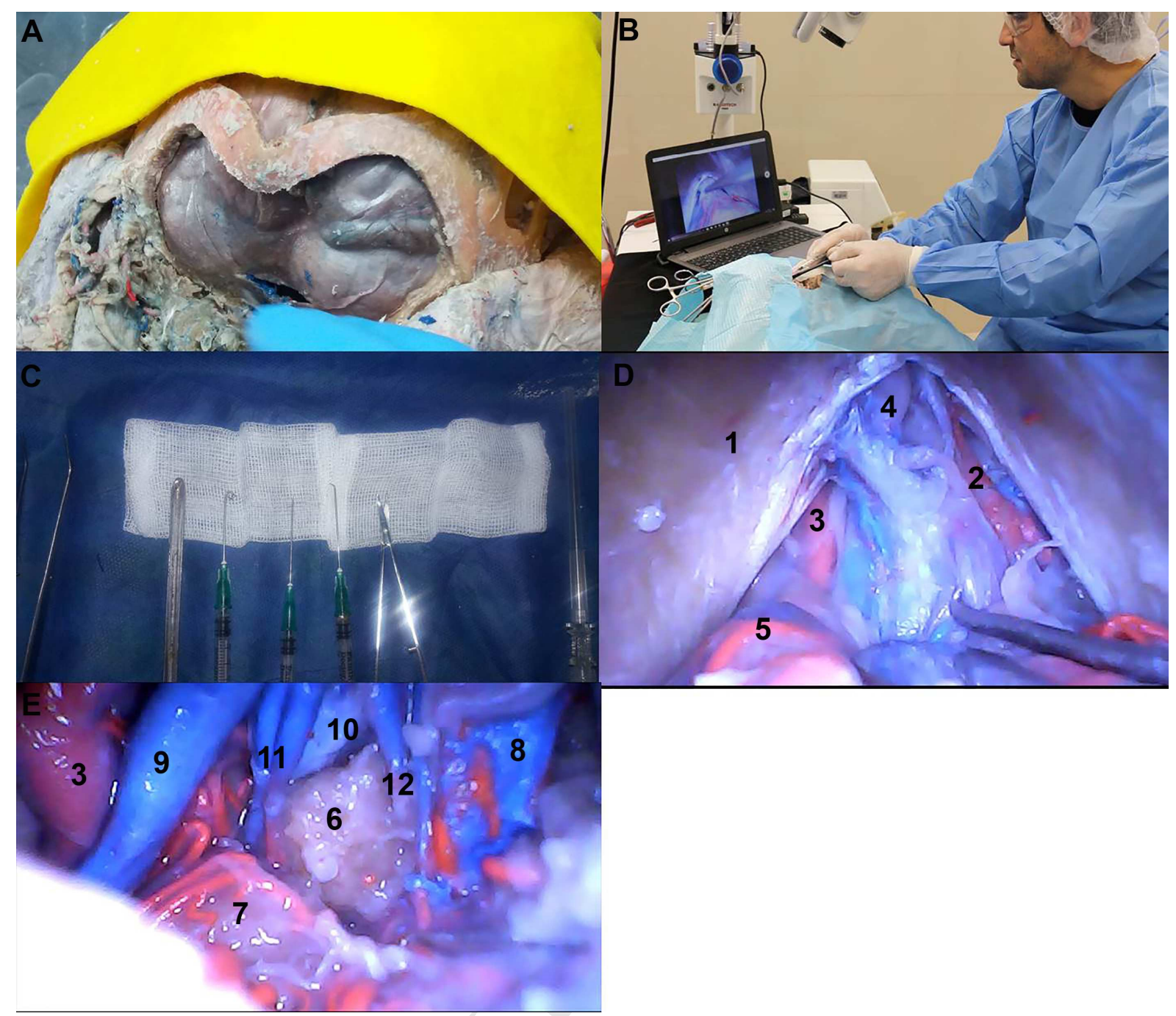




\section{Title}

Modified pure endoscopic approach to the pineal region: a proof of concept of an efficient and inexpensive surgical model based on laboratory dissections

\section{Highlights}

We present an inexpensive endoscopic surgical model using a borescope

A "borescopic" supracerebellar infratentorial approach was executed

An excellent exposure of the main pineal region neurovascular structures was achieved

In one of the specimen an incidental pineal cyst was removed 
Title

Modified pure endoscopic approach to the pineal region: a proof of concept of an efficient and inexpensive surgical model based on laboratory dissections

\section{Disclosure}

Prof. Juha Hernesniemi is an Aesculap consultant. The C. Ehrnrooth Foundation partially supports the present paper, which is part of the "Pineal region surgery" project. The authors have no personal financial or institutional interest in any of the drugs, materials, and devices described in this article. 
Title

Modified pure endoscopic approach to the pineal region: a proof of concept of an efficient and inexpensive surgical model based on laboratory dissections

\section{Abbreviations and Acronyms}

MAPEnd, modified pure endoscopic approach 